\title{
TITLE:
}

\section{$<$ NOTE $>$ A Short-Term Visit of an Adult Male Bonobo from the Neighboring Unit-group at Wamba}

\section{$\operatorname{AUTHOR}(\mathrm{S})$ :}

Toda, Kazuya; Tokuyama, Nahoko; Ishizuka, Shintaro; Furuichi, Takeshi

\section{CITATION:}

Toda, Kazuya ...[et al]. <NOTE>A Short-Term Visit of an Adult Male Bonobo from the Neighboring Unit-group at Wamba. Pan Africa News 2018, 25(2): 22-24

\section{ISSUE DATE:}

2018-12

URL:

http://hdl.handle.net/2433/236291

\section{RIGHT:}

Copyright (C) Pan Africa News. 


\title{
A Short-Term Visit of an Adult Male Bonobo from the Neighboring Unit-group at Wamba
}

\author{
Kazuya Toda ${ }^{1}$, Nahoko Tokuyama ${ }^{2}$, Shintaro Ishizuka ${ }^{1}$, \\ \& Takeshi Furuichi ${ }^{1}$ \\ 1 Primate Research Institute, Kyoto University, Japan \\ 2 The Graduate University for Advanced Studies, Hayama, Kanagawa, Japan \\ (E-mail: toda.kazuya.78x@st.kyoto-u.ac.jp)
}

\section{INTRODUCTION}

The social organization of male-philopatry is often explained by the importance of cooperation among kinrelated males to defend their group territories and the encompassed females against other neighboring groups (Williams et al. 2004; Furuichi 2006). Strong hostility between males of different groups may make male visit and immigration into neighboring groups extremely difficult. In chimpanzees (Pan troglodytes), there is a higher likelihood of intergroup killing when large male parties encounter smaller male parties or lone males of different groups (Wrangham 1999). In reality, visiting males (temporary immigrants, see Nishida et al. 1999) have been only observed twice in Bossou, Guinea (Sugiyama 1999) during the period of over 55 years observing wild chimpanzees at multiple study sites. It has been observed that male bonobos (Pan paniscus) have more tolerant relationships with out-group males than do male chimpanzees (Sakamaki et al. 2018). Therefore, the obstacles to visit or immigrate faced by bonobos might be less than those encountered by male chimpanzees. However, there has been only one report of male visits at Lomako (Hohmann 2001) and one report of male immigrations at Wamba, Democratic Republic of the Congo (Hashimoto et al. 2008). Here, we report an additional case of a temporary visit by an adult male bonobo from a neighboring group at Wamba. Moreover, the social condition and motivation of his visit are discussed referring to other cases of the Pan species in this report.

\section{BACKGROUND}

The observations in this report were collected from a group of wild bonobos, called PE, at Wamba, Luo Scientific Reserve, the Democratic Republic of the Congo, where long-term observations have been conducted since 1974 (Hashimoto et al. 2008). Since 1976, a bonobo group, called $\mathrm{P}$, was being studied occasionally until the interruption of all research in 1996 due to the civil war (Tokuyama \& Furuichi 2016). In September 2010, habituation and identification of bonobos in the antecedent P group's range were initiated. Researchers realized the existence of two independent groups ranging the area, and named these two groups PE and PW, respectively. The research was focused on the PE group with observations made on a daily basis (Sakamaki et al. 2018). It was suggested that the PE group is probably identical to the $\mathrm{P}$ group since two parous females from the $\mathrm{P}$ group were present in the PE group (Tokuyama \& Furuichi 2016). At the time of this report, the PE and PW groups consisted of 28 (including 9 adult females, 5 adult males, no adolescents) and 16

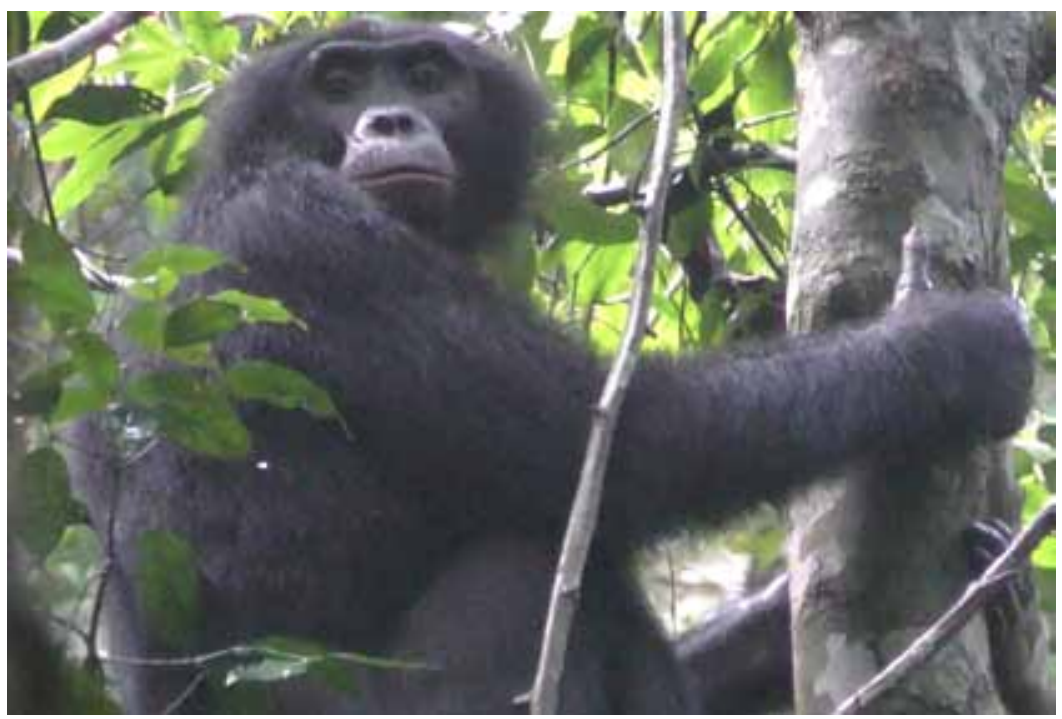

Figure 1. Terry was estimated to have been born in 2000 (17 years old at the time of this observation). 


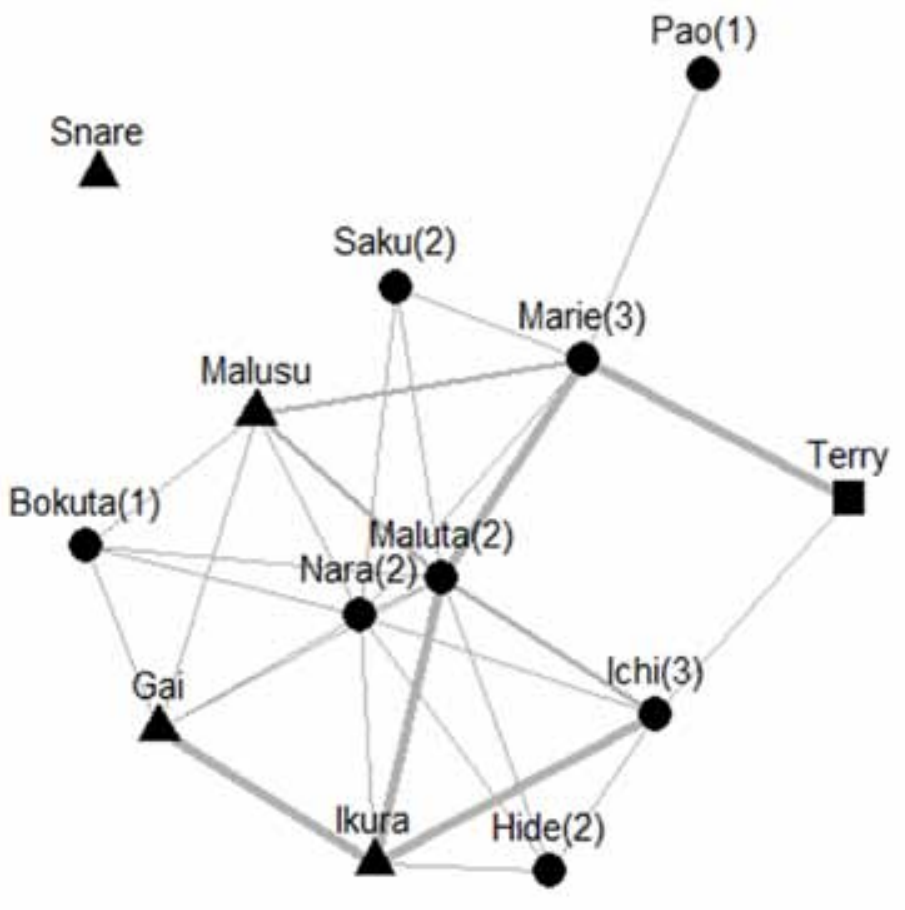

\section{Group_Sex - PE_Female $\boldsymbol{\Delta}$ PE_Male $\mathbf{D W}$ PWale}

Figure 2. Proximity network among individuals. The node shows an individual and its shape is classified by the group and sex of the individual. The edge shows a proximity between individuals and its thickness is related to the frequency of the proximity. The line thickness shows a number of the proximity between individuals at scans. The number in parenthesis means a score of the sexual skin in each female, (1) non-swelling, (2) intermediate swelling, and (3) maximal swelling.

individuals (including 7 adult females, no adolescent females, 3 adult males, 2 adolescent males), respectively. It was observed that the PE group frequently encounters the PW group (396 days in 1478 observational days between 2012 and 2015; Sakamaki et al. 2018). Additionally, one or two adult females of the PW group occasionally stay for a few days in the PE group after the other PW individuals apparently separated from the former (Tokuyama unpublished data). However, PW males had never been observed to remain in the PE group after the two groups separated. The visitor male of this report, named Terry, was identified in the PW group as an adolescent male on October 2012 (Figure 1). Although there was not sufficient data regarding the aggressive dyadic interactions required to assess the dominance hierarchy among the males of the PW group, Terry was apparently middle to low ranking in the group. KT, one of the authors, recorded all the perceived social interactions, as well as all individuals within visual range and within $5 \mathrm{~m}$ proximity at every $15 \mathrm{~min}$ scan on June 29, 2018.

\section{OBSERVATIONS}

On June 28, 2018, local assistants found Terry together with the individuals of the PE group at 16:59 $\mathrm{h}$ just before the night beds were made, although no other bonobos of the PW group had been observed since 14:44 h on June 26. On that day, the party of the PE group included all the individuals except for the alpha male, named Turkey, and his mother, named Kabo.

The next day, we arrived at the site at 06:07 $\mathrm{h}$ and found Terry getting out of his night bed at 06:46 h (Figure 1). His bed was made higher than others and was about $30 \mathrm{~m}$ away from the nearest bed of another adult female of the PE group. At 07:03 h, Terry exposed his erect penis and solicited an adult female, named Ichi, with maximal swelling. He was approached by Ichi, and they copulated with each other.

Terry was positioned at the periphery of the group during rest and travel. At 08:20 h, when the bonobos were feeding on the fruit of the Landolphia sp., a higherranking female, named Hide, chased Terry out. After he fled with a scream, the observers lost sight of Terry from where the other individuals were eating or resting.

At 11:43 h, Terry appeared again at a distance of about $50 \mathrm{~m}$ from where the PE bonobos were feeding on the Landolphia fruit at another location. At 11:52 h, Terry approached and sat within $5 \mathrm{~m}$ of an adult female with maximal swelling, called Marie. At 11:54, Terry solicited Marie with an erect penis and copulated with her. At 11:55 $\mathrm{h}$, Terry exchanged grooming with Marie for $43 \mathrm{~min}$.

At 12:38 h, when Marie and the other individuals climbed down from the trees and began to rest together on the ground, Terry was not in the vicinity. After this, Terry was not observed until August 8, 2018, when the party of the PE group encountered individuals of the PW group. In all, Terry had been observed in the proximity of only two 
adult females with maximal swelling (Figure 2).

\section{DISCUSSION}

Terry had approached two females with maximal swelling but kept a distance from the other PE individuals on the day we observed him. He seemed afraid of PE individuals, although aggression was not directed towards him by any PE males. The absence of an alpha male in the PE group may have facilitated Terry's visit, because higher-ranking males tend to behave more aggressively toward out-group males during intergroup encounters (Tokuyama et al. unpublished data). When the PE and PW groups frequently associate with each other, Terry was occasionally observed to have engaged in affiliative interactions with PE individuals (Tokuyama, unpublished data). Such affiliative interactions through intergroup encounters might be one of the reasons for the tolerance from the PE males towards Terry during his visit. There is a possibility that the PE and PW groups had divided from one group before 2010 when the intensive study of the PE group was initiated. Accordingly, Terry might have spent his childhood with the PE males. However, genetic analysis indicated that he had not been fathered and mothered by any PE individual, although one PW male remained his potential father (Ishizuka, unpublished data).

In this report, the sex ratio (the number of females to males) was a little higher in the PE group (1.8) than the PW group (1.4). Additionally, between June 23-24 (4-5 days before the observation of this report), there was only one female with maximal swelling among the seven females of the PW group. Terry copulated with two females of the PE group outside his own PW group. At Lomako, in a bonobo group called Eyengo, when the number of adult females to males had doubled compared to the previous years, two strange males visited for 12 months. One of the males had developed friendships with some Eyengo residents while receiving aggressions and copulated with one of the females three times (Hohmann 2001). These cases suggest that male bonobos might visit neighboring groups to seek additional mating opportunities.

In another case of bonobos at Wamba, four or five adult males and two females with infants had settled a study group, called E1, when some individuals of the E1 group disappeared and two neighboring groups ceased to exist probably due to poaching during the civil war (Hashimoto et al. 2008). However, in two chimpanzee groups at Mahale, Tanzania, called $\mathrm{K}$ and $\mathrm{M}$ groups, when $\mathrm{K}$ males had disappeared one by one, only $\mathrm{K}$ females visited or immigrated into the neighboring $M$ group with their dependent offspring (Nishida et al. 1985). These cases indicate that male bonobos might be more tolerant of strange males than are male chimpanzees.

At Bossou, two strange males had visited a study group living in an isolated forest, but they did not suffer particular aggression from resident males. In Bossou chimpanzees, intragroup male cooperation might be less intense than that in other chimpanzee groups. This is because they do not have competitive adjacent groups, while they compete within their own group for restricted resources in their fragmented ranging area (Sugiyama 1999). If the intragroup competition is greater than inter- group competition, male immigration might occasionally be a beneficial strategy.

In conclusion, Terry's temporary visit to a familiar neighboring group might have been a tactic to gain mating opportunities, which is possible among Wamba bonobos tolerant of neighbors.

\section{ACKNOWLEDGMENTS}

We thank the Ministry of Scientific Research of the D.R. Congo for the permission of bonobo research and the Research Center for Ecology and Forestry (CREF) in the Democratic Republic of the Congo for their support of our field studies in the Luo Scientific Reserve. We are also grateful to local assistants for providing great help with our fieldwork. We especially thank Tetsuya Sakamaki, a researcher of Wamba Committee for Bonobo Research (WCBR). Field research of KT was financially supported by the Leading Program of Primatology and Wildlife Science of Kyoto University, Grant-in-Aid for Scientific Research by the Japanese Society for Promotion of Science (17J01336), and a Young Explores Grant of National Geographic Foundation for Science and Exploration (Asia 38-16).

\section{REFERENCES}

Furuichi T 2006. Evolution of the social structure of Hominoids. In: Human Origins and Environmental Backgrounds. Ishida H, Tuttle R, Pickford M, Ogihara N, Nakatsukasa M (eds), Springer, Kyoto, pp. 235-248

Hashimoto C, Tashiro Y, Hibino E, et al. 2008. Longitudinal structure of a unit-group of bonobos: male philopatry and possible fusion of unit-groups. In: The Bonobos, Furuichi T, Thompson J (eds), Springer, New York, pp. 107-119.

Hohmann G 2001. Association and social interactions between strangers and residents in bonobos (Pan paniscus). Primates 42: 91-99.

https://doi.org/10.1007/BF02640692

Nishida T, Hiraiwa-Hasegawa M, Hasegawa T, Takahata Y 1985. Group extinction and female transfer in wild chimpanzees in the Mahale National Park, Tanzania. Ethology 67: 284-301. https://doi.org/10.1111/j.1439-0310.1985.tb01395x

Nishida T, Kano T, Goodall J, McGrew WC, Nakamura M 1999. Ethogram and ethnography of Mahale chimpanzees. Anthropol Sci 107: 141-188. https://doi.org/10.1537/ase.107.141

Sakamaki T, Ryu H, Toda K, Tokuyama N, Furuicih T 2018. Intergroup encounters in Wamba bonobos (Pan paniscus) at Wamba: frequent encounters occur at times of high fruit abundance. Int J Primatol 39: 685-704. https://doi.org/10.1007/s10764-018-0058-2

Sugiyama Y 1999. Socioecological factors of male chimpanzee migration at Bossou, Guinea. Primates 40: 61-68. https://doi.org/10.1007/BFO2557702

Tokuyama N, Furuichi T 2016. Do friends help each other? Patterns of female coalition formation in wild bonobos at Wamba. Anim Behav 119: 27-35. https://doi.org/10.1016/janbehav.2016.06.021

Williams JM, Oehlert GW, Carlis JV, Pusey AE 2004. Why do male chimpanzees defend a group range? Anim Behav 68: $523-532$. https://doi.org/10.1016/janbehav.2003.09.015

Wrangham RW 1999. Evolution of coalitionary killing. Yearb Phys Anthropol 42: 1-30. https://doi.org/133.3.201.101

Received: 18 November 2018 Accepted: 17 December 2018 